\title{
Open Service Innovation in Smart Cities: A Framework for Exploring Innovation Networks in the Development of New City Services
}

\author{
Luisa Errichiello ${ }^{1, a}$, Alessandra Marasco ${ }^{1, b}$ \\ ${ }^{1}$ Institute for Service Industry Research (IRAT) - National Research Council (CNR), Naples, Italy \\ a.errichiello@irat.cnr.it, ba.marasco@irat.cnr.it
}

Keywords: Smart City; Open Innovation; Service Innovation, Public-Private Innovation Networks in Services.

\begin{abstract}
The paper presents a multi-dimensional framework for exploring the drivers, structure and dynamics of public-private service innovation networks in the Smart City context and their innovation outcomes at the project, network and city levels. The framework provides a conceptual contribution to the increasingly relevant issue of open innovation in smart cities by leveraging the interpretive potential of the open service innovation perspective, namely the concept of PublicPrivate Innovation Networks in Services (ServPPINs), to advance the understanding of complex interactive structures and processes involved in the development of new services for smart users.
\end{abstract}

\section{Introduction}

Recent years witnessed an increasing interest in the effective implementation of the Smart City concept in response to the challenges of sustainable socio-economic and urban development, global competitiveness and improved quality of life. In this direction, several studies and initiatives point to the relevance of open innovation to cities' pathway for becoming smarter. This paradigm can support the creation of an urban innovation ecosystem for the development of advanced city services by stimulating and facilitating the synergistic contribution of business, public sector and citizens to innovation processes. Notwithstanding the growing attention to the potential of open innovation in the smart city context, the understanding of the features and dynamics of smart innovation networks is still limited. This paper aims at contributing in this direction by leveraging the interpretive potential of the open service innovation perspective. Indeed, recent literature on innovation in services emphasizes the role of interactive structures between public, private and third-sector organisations for the development of new and improved services, namely Public-Private Innovation Networks in Services (ServPPINs), in relation to societal challenges. Based on this concept, the paper proposes a multi-dimensional framework for exploring the drivers, features, dynamics and outcomes of "smartServPPINs", thus providing a conceptual contribution to the field of smart city innovation.

The paper is structured as follows. The next section examines the literature on open innovation in smart cities, highlighting the main issues and challenges related to the implementation of this paradigm in this context. The service innovation perspective, notably the ServPPINs concept, is then introduced as a useful lens to advance the understanding of the complex nature and functioning of innovation networks in smart cities. Against this background, the subsequent section presents a conceptual framework for exploring smartServPPINs, which identifies the key dimensions to be investigated for understanding the factors influencing the effective functioning and the role of innovation networks to realize innovations for cities' smart development. Finally, in the last section some conclusions and directions for future research are provided.

\section{Smart Cities and Open Innovation}

Open innovation is increasingly advocated as a powerful driver of cities' smart transformation. This paradigm calls for firms to draw on knowledge flows outside their boundaries to accelerate internal innovative processes and expand the markets for external use of innovation, emphasizing 
interorganizational collaboration and networking for knowledge exchange and increased innovativeness [1]. Though originated in the industry, open innovation is highly relevant also to the smart city context, as collaboration, co-creation and co-development are key ingredients of the journey to build the cities of the future [2]. Open or networked innovation supports the smarter development of cities opening the boundaries between government, firms and society so as to transfer innovation inwards and outwards in the urban area and to boost research, development and delivery of advanced services that meet the needs of the users in the urban environment [3]. Also the current European Commission programs stimulate experimentation into smart cities as open and user-driven innovation ecosystems for designing and piloting innovative solutions based on the collaboration between citizens, firms and local governments [4].

For the development of open innovation in smart cities, two levels of collaboration can be distinguished [5], namely institutional collaboration at the territorial level for creating effective conditions for sustainable innovation; and operational collaboration within innovation processes around specific opportunities. The challenge at the first level is to create a collaborative approach for shaping the innovation ecosystem based on sustainable partnerships among the main stakeholders involved in urban development, while the main issue at the second layer concerns the effectiveness of collaboration networks for urban innovation processes, namely in sharing different resources, governing co-development processes and fostering knowledge flows within innovation projects. Both levels of collaboration and their interaction are important to foster the development towards open innovation for smart cities. However, most studies seem to focus on collaborative approaches at the institutional level [e.g. 6, 7, 8, 9], stressing the key role of public-private partnerships in urban planning for achieving a shared vision and aligning them to the real needs of city's users. Moreover, studies on networked innovation for smart cities are mostly technologyoriented, focusing on its outcomes in terms of new technologies and e-service applications. While technological innovation is a necessary condition to make a city smart, the development and adoption of up-to-date technologies per se does not guarantee the success of smart cities initiatives. Indeed, the challenge of smart city innovation is not primarily on technology, but on service transformation and improvement since the ultimate goal of a smart city is to enhance the overall quality of city services. This calls for a more comprehensive view of innovation, including also the non-technological human, organizational and political changes associated with the innovative fulfillment of city's service demands [10]. Such a broader view is in line with the concept of social innovation, which is increasingly emphasized within current smart city programs and initiatives (e.g. URBACT II, Periphèria, Human Smart City movement). Core to social innovation for smarter cities is the co-production of socially innovative solutions to urban problems with a strong involvement of citizens and non-governmental associations and the diffusion of innovative models of cooperation and social relationships to improve service quality [11].

By this brief review, it appears that further understanding of the complex nature and dynamics of collaborative innovation in the smart city context would benefit from additional efforts to better take into account the interplay between the institutional and the operational layers of collaboration, the interorganizational structures involved in innovation processes and the non-technological, social dimensions of innovation.

\section{Open Service Innovation for Smart Cities: Overcoming the Gap}

The literature on innovation in services has emphasised the role of interactive structures and processes in relation to the general perspective of open innovation, also within the context of public services [12]. Recent studies in this area pay a growing attention to innovation models for the public sector, given the increasing complexity underlying the goal of public value creation for service users, citizens and society as a whole in an era of economic and financial crisis where traditional mechanisms of public provision such as the State and the Market are no more adequate. In particular, it is highlighted that innovative solutions to modern challenges can be effectively 
developed, promoted and maintained through multi-actor collaborative structures that enable public, private, third-sector and civil society actors to interact in a complementary and synergistic way in joint innovation processes [13]. In this viewpoint, Public-Private Innovation Networks in Services, labelled ServPPINs, have been suggested as a viable alternative for realising innovations to existing models, such as public-private partnerships. ServPPINs involve collaborative partnerships between public, private and third-sector actors for developing, producing and delivering new and improved services. They are flexible interorganizational structures that support the exploitation of complementarities and synergies among different organisations, the integration and sharing of dispersed knowledge, technology, competences and potential risks in uncertain innovation processes. ServPPINs are a specific type of innovation networks, being characterised by three fundamental features: firstly, the interaction between public and non-market actors and private actors occupies a central role; secondly, service providers as the main actors in the networks; and, finally, they build upon a broad conceptualization of innovation, including also non-technological forms (i.e. organizational, process, cognitive, conceptual, network-based). Moreover, they are "naturally" characterized by customer/user interactivity and involvement in innovation processes, given the endogenous role of customers in service co-production. The relational configuration of ServPPINs can widely vary depending on the actors involved, their role and the degree of formality of relationships among them. Further, it is subject to change during the networks' lifecycle, which can be described in terms of the three main phases of initiation, emergence and wider implementation or uptake [14]. Empirical research on the structure and operation of these networks in transport, health, tourism, knowledge-intensive and public services highlights that their success is determined by four main interrelated sources [15]: a) the role of both internal and external drivers, including trust, pro-innovation culture, leadership, a right strategy between bottom-up or top-bottom approaches, financial and political support, technological opportunities and policies concerning innovation, public procurement, employment and skills, sectoral development; b) the integration within wider systemic and social networks; c) the ability to overcome barriers in areas such as the rigidity of public administrations, the existence of different interests and incentive systems, free riding, asymmetric information and networking competences, appropriability; d) the reduction of evolutionary inefficiencies, concerning the risk of not being efficient enough to adapt to the changing phases of networks' lifecycle. Moreover, it has been shown that these structures for open service innovation represent a suitable organisational mode for social innovation, facilitating the collective creation process necessary for the development of new solutions to societal needs [16, 17].

For their features, ServPPINs can be seen as a valuable concept to explore innovation networks in smart cities and advance the understanding of key factors influencing their effective operation and their role in realising innovations for cities' development. Indeed, these new interorganizational arrangements take into account the way in which multiple public, private, third-sector and civic actors interact to produce not only technological innovations but also social innovations. Thus, they allow to address public-private collaboration in a more comprehensive view, which takes into account the complexity of collaborative innovation in the context under examination, in terms of actors' heterogeneity, relationships dynamism and variety of innovation outcomes.

\section{A Framework for Exploring Innovation Networks in Smart Cities}

Based on the current research on open innovation in smart cities and on ServPPINs, a multidimensional conceptual framework is proposed for exploring the drivers, structure, dynamics and outcomes of smart service innovation networks. The framework (Figure 1) identifies the key dimensions to be investigated for understanding the factors influencing the effective functioning and role of "smartServPPINs". More in detail, these include: (1) the institutional context which frames the emergence and functioning of smartServPPINs; (2) the drivers and enablers of multiactor collaboration at the operational level of the innovation network; (3) the structure and innovation 
activities of smartServPPINs; and (4) the short-term and long-term innovation outcomes. Moreover, a temporal dimension related to the network's life-time or cycle is included in the framework in order to consider temporal changes in the network's structural features and related innovation activities. The dimensions of the framework and their components are described below.



Fig. 1: The conceptual framework

The Smart City Institutional Context. Institutional forces can act both as drivers or barriers of smartServPPINs start-up and sustainability over time, being conducive or detrimental to entrepreneurship, collaboration and innovation [5,13,15]. In general terms, the institutional framework can be conceptualized as a multi-layered system including [13,18]: 1) laws and regulations regarding socio-economic and environmental concerns, established at local, national or extra-national level and shaping firms and business strategies and behaviors; 2) technology and innovation policies within specific sectors (ICT, transport and logistics, high-tech industries, etc.) established to set appropriability regimes, protect innovation and provide financial incentives and public research funding; 3) government investments, mainly in technological infrastructures and educational/training programs; 4) cultural and social norms, in terms of business climate, entrepreneurial spirit, or the diffusion of a pro-innovation culture at the city level. In the initial stage 
of a smart city strategy formulation, the existence of policies and measures supporting innovation and collaboration would positively impact on the successful initiation of specific initiatives and projects. In the case of Barcellona, for example, the Smart City initiative is just one part of an advanced conceptual model of urban transformation towards a knowledge-intensive city pursued through several policies and investments promoting innovation, entrepreneuship and collaborative approaches between companies, institutions and citizens [6]. With specific regard to the context of smart cities, the institutional system can be thus referred to the set of rules, norms and relativelystable conditions that shape a number of key smartness areas, directly affecting the overall "endowements" of a smart city [19]: 1) smart economy; 2) smart mobility; 3) smart environment; 4) smart living; 5) smart governance; 6) smart people. The level of commitment to act along one or more smartness dimensions would reflect a different maturity of the city in relation to its developmental pathway towards smartness. Specifically, moving from a "scattered" (i.e. focused on one or few areas) to a fully "connected" (i.e. focused on all the six areas) approach, the level of integration, coordination and interaction among smart initiatives and projects would increase. In the case of Barcelona, the city is committed to act along all the six smartness dimensions and this "connected" maturity approach fosters synergies among projects and their social outcomes [20]. Therefore, it is expected that the more connected the smart city model adopted, the higher the power of transforming the existing institutional realm, producing positive system-level effects.

Enablers and Drivers of SmartServPPINs. A number of external and internal factors influence the set up and the dynamics of innovation networks, constituting enabling conditions or drivers of collaboration around specific innovation opportunities [15]. External factors are directly influenced by the institutional context and include the political support from public institutions and the availability of funding opportunities for specific projects. Public effort to encourage collaboration in smart city innovation projects can manifest through many actions, such as the launch of awareness campaigns, communication plans, the creation of committees or agencies, the assessment and involvement of local stakeholders, the active consultation of local people, the institution of monitoring systems for initiated projects [2]. Funding can be directly allocated to projects or, alternatively, to broader smart city initiatives and then assigned to specific projects. Financial support can be provided by a number of bodies, operating at different geographical scale, such as European Commission Programmes (e.g. FP7, CIP) and Fund for Regional Development, large private firms, district and cities' governments or even the citizens' themselves through crowdfunding initiatives. The Amsterdam Smart City (ASC) platform offers a valuable example to understand how public interest and concern and the availability of funding opportunities are vital elements to encourage network-based collaboration. Started in 2009, the ASC platform is a partnership including over 70 participants among private firms, local authorities, research institution and the civil society. The founding members of the platform - the Amsterdam Innovation Motor (AIM), the city of Amsterdam and two IT private firms - are often directly involved in many innovation networks build around specific opportunities [21]. Through the pro-active action of its founders and promoters, the platform is thus able to build commitment among stakeholders, initiates and stimulates innovation projects along with ensuring them the necessary financial resources to be successfully developed.

With regard to internal factors, which found lay within the relational network of potential participants in the innovation project, some can be considered sine qua non conditions of collaboration since their existence is crucial for the formation and nourishment of innovation networks formed by a variety of public and private stakeholders, who can operate in different sectors and have different cognitive schemes, attitudes and behaviors. These include [8,13, 25, 22]: mutual trust, leadership, commensurability and non-rivalry of needs and interests, complementarity of competences. While it is widely recognized that trust is a precondition for initiating collaboration at inter-organizational level, innovation networks can also start with low degree of mutual trust, since what is really crucial for successful collaboration is trust building along the innovation development process $[23,24]$. In this respect, the ASC Platform provides an excellent example of 
how a "trusted advisor" role can accelerate innovation initiatives and collaboration. ASC has built its public trustworthiness over the past two years by acting without any "personal and financial interests" with the goal of bringing interested parties together and foster collaboration among them. Though interacting with its partners, the platform has increasingly familiarized with organizations' specific interests and this enabled it to successfully create matches between the different goals and expectations of potential participants in specific innovation projects [21]. In this way it has also secured other key enabling factors of innovation networks, i.e. commensurability, non-rivalry of interests and needs as well as the complementarity of competences among participants. Prior relationships or integration in existing social networks at both local and extra-local level (structural embeddedness) are important for facilitating the formation and maintainance of collaborative innovation networks, since it is often through them that partners can judge the trustworthiness of other potential partners $[22,23]$, increase their attitude towards risk-taking and a pro-innovation orientation. In this respect, a valuable example is provided by the Smart City of Manchester. Indeed, before the Manchester's Digital Strategy established the ambitious goal of making Manchester a leading digital city, a number of projects and initiatives had already been launched to increase the city innovative capacity and promote cross-sector local networks of innovation. Among these, the Innovation Manchester - founded in 2008 by the not-profit organization Manchester Knowledge Capital partnership - brought together over 70 among local top business leaders and key city partners, who acted as champions to develop ideas for innovation in the city's main business sectors, such as advanced manufacturing, digital technology, creative and biomedical [25]. Activating networks of collaboration, these initiatives have arguably contributed to creating a proinnovation environment and prepared the ground for subsequent Smart City services and projects. A similar facilitating role has been played by the city's participation in a number of extra-local initiatives carried on by the Manchester Digital Development Agency, a partnership between governments, businesses, universities and citizens founded to develop the city's Digital Strategy, that played the role of coordinator partner in several European Smart City initiatives [21].

SmartServPPINs Structure and Activities. The structure and process conditions of SmartServPPINs for realising specific innovation opportunities can be described in terms of roles of different actors, their competencies and contribution to the different stages/activities of the innovation process, the forms of partnership arrangements, the governance and interaction mechanisms, the duration and scale of the innovation projects and its financial, technological and knowledge resources. In particular, the structure and operation of SmartServPPINs can be characterized by a "caretaker" mode, in which one actor plays the role of conductor, hub actor or systems integrator, or by a "distributed" nature, in which responsibilities are more diffused among the actors. Moreover, their functioning can be based on a top-down approach, driven by public action, as well as by bottom-up initiative, based by the voluntary engagement of other actors [14]. In Amsterdam Smart City, for example, the Climate Street project, aimed at testing innovative technologies, logistics and energy management solutions for making the city's shopping streets more sustainable, was characterized by key role of the Utrechtsestraat Business Association as the initiator and champion of the innovation process. A small group of entrepreneurs in the street, motivated to increase its attractiveness, joined forces to start the project and formed the core of the partnership between the municipal organization and the other technical development partners like JCDecaux, Philips, TNT, Vodafone. In the initial phase of the project, only a small group of entrepreneurs were involved through a pilot run and then the spill-over effect to other groups in the street was leveraged for a full-scale adoption of the new solutions. The small group of "pioneers" served as ambassadors for the project and promoted its benefits, thereby supporting the uptake of the project by other entrepreneurs in the street. Furthermore, face to face communication with the local entrepreneurs, which was also facilitated by the champion role of the manager of the street business association, proved to be essential to promote strong commitment to the sustainability goals. Differently, the Ship-to-grid project was commissioned and lead by the Port of Amsterdam under the goal of becoming one of the most sustainable harbours in Europe by 2020. The network 
comprised many stakeholders from the municipality and several service providers with complementary competences (ICT infrastructure, engineering, grid operator). To obtain standardisation for the ship to grid solution, the port of Amsterdam worked closely also with the National Port Council and the World Port Climate Initiative. In this case, a top-down approach was evident, allowing to ensure the effective coordination of a high number of different organizations with different levels of commitment $[2,21]$. Often SmartServPPINs are configured as living labs, which assign a central role to end-users from the early stage throughout the innovation process. Living labs allow communities of users/citizens to co-create, explore, experiment and validate new solutions based on technology platforms such as Future Internet experimental facilities involving industry, academia and public stakeholders. The experimentation of the living lab approach for accelerating the user-driven development of Internet-enabled services is at the basis of many European FP7-ICT projects (e.g. TEFIS, ELLIOT, Apollon) and many smart cities are deploying most of their innovation efforts through the creation of living labs for developing a vast array of urban innovative solutions. SmartSantander provides a key example in this regard, with its commitment to the creation of a city-scale experimental living laboratory for new applications in a range of areas (parking spaces and traffic control, environmental management and monitoring, public transportation, social assistance etc.) based on the early involvement of real end-users in the experimentation process [26].

Innovation outcomes. Performance outcomes of smartServPPINs can be conceptualized through a multi-dimensional and multi-level categorization. Specifically, we can identify innovation outcomes at three interrelated levels: 1) the innovative solution realized through the project; 2) the network; 3) the city. As to the first level, the type of innovation (e.g. technological, nontechnological), its degree of novelty and replicability are the most significant elements to consider. Developing new technological solutions, such as electronic management systems, digital platforms and e-service applications is a key objective for many smart city initiatives. Very often, however, the development of new applications or the adoption of advanced technologies in smart city projects is primarily considered as the enabling condition for other (central) innovation outputs: service innovations, i.e. the development of new services for citizens, or commuters and travelers, such as new energy-efficient services (e.g. the ITO Tower project in Amsterdam Smart City), intelligent parking systems (e.g. the Smart Parking Network project in Barcelona Smart City), new mobility solutions, like e-car sharing and e-bike service (e.g. the eMorail project in Vienna Smart City); social innovations, i.e. the behavioral change of citizens, for example through the reduction of their energy usage (e.g. the Digital Home Environment Energy Management system in Manchester Smart City) or the community involvement in public plan-making, formal decision making and implementation (e.g. the Helsinki Regional Infoshare project); network-based innovation, i.e. when the establishment of a smartServPPIN is the main goal of the project (e.g. the Ship-to-Grid project in Amsterdam Smart City). In this last example, in particular, the degree of novelty in the ICT components (ship-to-grid connection points for inland ships in the Amsterdam harbour) was quite low, while the establishment of a new collaborative arrangement (organizational innovation) between a number of organizations (both private and public) with different levels of commitment was the main outcome of the project [21]. Finally, the replicability of the innovative solution is linked to the possibility of increasing the size of the related project by involving more stakeholders (also from different cities), funding and services (scaling of the project), or extending the geographical area of application/adoption of the solution within the same city or, more ambitiously, in other smart cities [2]. In this respect, the creation of a wide collaborative platform to ensure that Smart City projects are rolled out in a replicable way is, for example, a fundamental pillar of the Barcelona Smart City vision [27] and has allowed the extension to more areas in the city and scalability of new solutions (e.g. Integral Solution of Urban Infrastructure, Media-tic Building). At network level, the main innovation outcomes can be primarily measured in terms of acquisition of new skills and competences by participants in the innovation network (learning) and increased social capital, especially in the form of accrued mutual trust. Acquiring new knowledge is key for 
both private and public organizations, as it increases their innovation capability and also foster knowledge transfer across different innovation projects, since a specific partner would operate as a knowledge gatekeeper from one project to another. In a similar way, if trust building is a matched goal of project-based collaboration, this will reveal a crucial intangible asset for starting new innovation projects with the trusted partners. At city level, the overall goal of any smart city strategy would always be to realize, through a portfolio of relevant initiatives and innovation projects, significant economic (e.g. new job opportunities, new businesses), social (e.g. better health, time savings, democratic governance) and environmental (energy saving and lower Co2 emissions) outcomes. In the city of Helsinki, for example, the e-government Open Data BNC project has improved and simplified the access to administrative services thereby saving citizens' time and travel costs (social impact), reducing traffic and gas emissions (environmental impact). Moreover, the opening of public data to the citizens' and companies would enable the development of new business models and new services (economic impact). It is clear that while long-term impact of innovations has to be evaluated through cost-benefit analysis, in the short-term a main intangible outcome can be the creation of awareness among citizens and local stakeholders of innovation and sustainability goals [2]. In the case of Amsterdam Climate Project, the energy saving goal of 661 ton Co2 per year was not achieved after two years from its pilot stage (2009-2011), but the city municipality still considered it to be successful since it significantly contributed to create more awareness and interest among citizens and companies about environmental issues [21].

\section{Conclusions and Further Research}

The purpose of this paper is to provide an initial conceptual contribution to the increasingly relevant issue of open innovation within the smart city context by leveraging the interpretive potential of the service innovation perspective, namely the concept of ServPPINs, drawing on the research stream disclosed by Gallouj and colleagues in recent years. These public-private innovation networks in services enrich the traditional concepts of innovation networks and public-private partnerships and are a new means of approaching, from a network-based perspective, a field of innovation that is still largely underexploited, namely innovation in public services [14]. Thus, it is believed that ServPPINs can provide a useful lens to advance the understanding of networked innovation within the complex and fast-changing landscape of smart cities, by better addressing the complexity of interactions between public, private, third-sector organisations and users/citizens communities in the development of innovative social services. Based on this concept, the paper proposes a multidimensional conceptual framework for exploring institutional, organizational and process conditions of "SmartServPPINs" in realizing opportunities for technological as well as nontechnological innovations in the smart city context.

Further research will be directed to test and refine the proposed framework through multiple case studies of public-private service innovation networks in smart cities. In-depth multiple case study analysis is expected to shed light on the features and patterns of SmartServPPINs and allow the identification of factors influencing their success, in terms of short-term and long-term innovation outcomes. Such an analysis will be also aimed at a improving the understanding of the role of city users/citizens within innovation processes for the development of new city services. Through crosscase analysis, the research would thus contribute to advancing knowledge on innovation in smart cities, at the crossroad of open innovation, social innovation and service economy. As to the managerial implications, a better understanding of the role and functioning of SmartServPPINs is necessary for implementing a successful smart city strategy that is based on effective collaboration among different stakeholders and on citizens involvement in the development of new city services. In this regard, the case analysis would provide useful insights for the effective set up, management and diffusion of open innovation models that are functional to the smart transformation of cities. 


\section{References}

[1] H. W. Chesbrough, W. Vanhaverbeke and J. West: Open Innovation: Researching a New Paradigm, Oxford University Press, Oxford (2006)

[2] European Parliament Committee for Industry, Research and Energy (ITRE): Mapping Smart Cities in the EU, Directorate General for Internal Policies, Policy Department A: Economic and Scientific Policy (2014)

[3] K.A. Paskaleva: The smart city: A nexus for open innovation? Intelligent Buildings International Vol. 3 (2011), p. 153-171

[4] H. Schaffers, N. Komninos and M. Pallot: Smart Cities as Innovation Ecosystems Sustained by the Future Internet, FIREBALL Project White paper (2012)

[5] H. Schaffers, N. Komninos, M. Pallot, B. Trousse, M. Nilsson and A. Oliveira: Smart Cities and the Future Internet: Towards Cooperation Frameworks for Open Innovation, in: The Future Internet - Future Internet Assembly: Achievements and Technological Promises, edited by J. Domingue, Springer Berlin Heidelberg (2011)

[6] T. Bakici, E. Almirall and J. Wareham: A Smart City Initiative: the Case of Barcelona,.J. Knowl. Econ. Vol. 4 (2013), p. 135-148

[7] C. Bevilacqua, G. Esposito and C. Trillo: Evaluation of PPP performance: a comparative analysis of 12 case studies in the Boston Metropolitan Area, in: CLUDs Project First Scientific Report, Economic Development Strategies - The Role of Public Private Partnership (2012)

[8] K. Emerson, K. T. Nabatchi and S. Balogh: An Integrative Framework for Collaborative Governance. Journal of Public Administration Research and Theory Vol. 22 (2011), p. 1-29.

[9] S.T. Ng, J.M. Wong and K.W. Wong: A public private people partnerships (P4) process framework for infrastructure development in Hong Kong. Cities Vol. 31 (2013), p. 370-381

[10] T. Nam and T.A. Pardo: Smart city as urban innovation: focusing on management, policy, and context, In: Proceedings of the 5th International Conference on Theory and Practice of Electronic Governance, edited by E. Estevez and M. Janssen, ACM, New York (2011)

[11] P. Ramsden: Social Innovation for Smart Cities: the state of the art, URBACT II Baseline Study (2012)

[12] F. Djellal, F. Gallouj and I. Miles: Two decades of research on innovation in services: Which place for public services? Structural Change and Economic Dynamics Vol. 27 (2013), p. 98117

[13] K. M. Weber, B. Heller-Schuh, H. Godoe and R. Roeste: ICT-enabled system innovations in public services: Experiences from intelligent transport systems, Telecommunications Policy (in press), Available online 27 January 2014, http://dx.doi.org/10.1016/j.telpol.2013.12.004

[14] F. Gallouj, L. Rubalcaba and P. Windrum: Public-Private Innovation Networks in Services, Edward Elgar Publishing Ltd, Cheltenham (2013)

[15] L. Rubalcaba, P. Windrum, F. Gallouj, G. Di Meglio, A. Pyka, J. Sundbo and M. Webber: ServPPIN. The contribution of public and private services to European growth and welfare and the role of public-private innovation networks. ServPPIN project final report, Universidad de Alcalá (2011)

[16] F. Djellal and F. Gallouj: Social innovation and service innovation, Conference Challenge Social Innovation, Vienna (2011) 
[17] L. Rubacalba, G. Di Meglio and G. Gallego: Public-private Innovation networks and social innovation in the service economy, in: Social Innovation: New Forms of Organisation in Knowledge-Based Societies, edited by C.R. Viñals, C. Parra Rodríguez, Routledge (2013)

[18] J. Zhang and X. Liang: Promoting green ICT in China: A framework based on innovation system approaches, Telecommunications Policy Vol. 36 (2012), p. 997-1013

[19] Centre of Regional Science, Vienna University of Technology: Smart cities Ranking of European medium-sized cities, Final report (2007)

[20] R. Achaerandio, R. Bigliani , J. Curto and G. Gallotti: Smart Cities Analysis in Spain 2012 The Smart Journey, White paper, IDC (2012)

[21] Amsterdam Smart City: Smart Stories (2011). Information on http://www.amsterdamsmartcity.com/

[22] J.M. Bryson. and B.C. Crosby: Design and Implementation of Cross-Sector Collaborations: Propositions from the Literature. Public Administration Review Vol. 12 (2006), p. 44-55

[23] P.S. Ring and A.H. Van de Ven: Developmental Processes of Cooperative Interorganizational Relationships. Academy of Management Review Vol. 19 (1994), p. 90-118

[24] S. Vange and C. Huxham: Nurturing Collaborative Relations Building Trust in Interorganizational Collaboration. Journal of App. Behavioral Science Vol. 39 (2003), p. 15-31

[25] Manchester Knowledge Capital: Manchester City Region Innovation Prospectus, Final report (2009). Information on http://www.manchesterknowledge.com/knowledge-bank/innovationprospectus/

[26] H., Schaffers, N. Komninos., M. Pallot, B. Trousse, M. Nilsson and A. Oliveira: Integrating Living Labs with Future Internet Experimental Platforms for Co-creating Services within Smart Cities, in: Proceedings of the ICE Conference, Aachen, Germany (2011)

[27] R.Y. Clarke: Smart Cities and the Internet of Everything: The Foundation for Delivering NextGeneration Citizen Services, White paper, Cisco (2013) 